\title{
Penerapan Single Exponential Smoothing (SES) dalam Perhitungan Jumlah Permintaan Air Mineral Pada PT. Akasha Wira International
}

\author{
Lolyka Dewi Indrasari*1 \\ ${ }^{1}$ Program Studi Teknik Industri, Fakultas Teknik, Universitas Kadiri \\ Email: lolyka@unik-kediri.ac.id ${ }^{1}$
}

\begin{tabular}{|c|}
\hline InformasiArtikel \\
\hline $\begin{array}{l}\text { Riwayat Artikel : } \\
\text { Received : } 7 \text { - Maret - } 2020 \\
\text { Revised : } 5 \text { - April - } 2020 \\
\text { Accepted : } 21 \text { - April - } 2020\end{array}$ \\
\hline
\end{tabular}

\section{Kata kunci :}

Calculation of the number of requests

Mean Absolute Deviation

Single Exponential Smoothing

Shortneck

Mean Absolute Deviation

Untuk melakukan sitasi pada penelitian ini dengan format: P. D. Sugiyono, metode penelitian kuantitatif, kualitatif,dan $R \& D$. 2016

\begin{abstract}
A b s tract
The purpose of this study was to determine the forecasting of the number of requests for $330 \mathrm{ml}$ shortneck mineral water products in the future using the Single Exponential Smoothing (SES) method. Limitation of the problem is discussing the number of requests in the first half of 2020, the data used were obtained from PT. Akasha Wira International from January 2014 to December 2019. The analytical method is to calculate the forecast error value of the different $\alpha$ values to find one value that produces the smallest error with the calculation method Mean Absolute Deviation (MAD) and Single Exponential Smoothing (SES) can interpreted based on the calculation stage where the forecast data value in the period $t$ +1 is the actual value in the period $t$ plus the adjustment derived from forecasting error that occurred in the period $t$. The results obtained on the value of Mean Absolute Deviation $(M A D)$ are taken at $a=0.9$ because it produces the smallest value of the projected data projection error of 1860 units. Whereas in forecasting requests using Single Exponential Smoothing (SES), $330 \mathrm{ml}$ shortneck mineral water in the first half of 2020 amounted to 2177634 units.
\end{abstract}


disesuaikan berasal dari kesalahan nilai peramalan yang terjadi pada periode $t$. Didapatkan hasil pada nilai Mean Absolute Deviation (MAD) diambil pada a = 0,9 karena menghasilkan nilai kesalahan proyeksi data pemrintaan paling kecil yaitu 1860 unit. Sedangkan pada peramalan permintaan menggunakan Single Exponential Smoothing (SES), air mineral $330 \mathrm{ml}$ shortneck pada semester I tahun 2020 sebesar 2177634 unit.

\section{Pendahuluan}

Era modern saat ini, masyarakat lebih gemar melakukan pembelian barang di beberapa tempat untuk kebutuhan sehari-hari. Kebutuhan sehari-hari yang tidak ternilai harganya tapi berguna bagi kesehatan salah satunya adalah air mineral [1]. Kebutuhan air mineral meningkat seiring dengan tingginya permintaan pada pasar [2], [1]. Permintaan tersebut meningkat karena masyarakat saat ini, sudah berpikir untuk hidup sehat dan praktis. Dengan adanya air minum dalam kemasan, akan mempermudah masyarakat untuk membeli diluar rumah jika hendak bepergian dan tidak sempat mempersiapkan dirumah. Air minum dalam kemasan botol salah satunya, yaitu banyak tersedia disupermarket, took- toko retail bahkan toko kelontong dengan berbagai jenis volume dan merk. Konsumsi air mineral semakin hari semakin tinggi, oleh sebab itu perusahaan yang memproduksi perlu melakukan persediaan agar permintaan dapat terpenuhi [3]. Air mineral yang dibutuhkan oleh konsumen setiap bulannya pada sebuah tokotoko berbeda unit yang terjual, jika toko- toko ataupun distributor tidak mampu melakukan pemasaran penjualan, pihak produsen akan mengalami kerugian secara finansial dan operasional. Kerugian secara finansial yaitu terkait dengan biaya bahan baku yang digunakan untuk melakukan produksi, sedangkan operasional adalah kerugian yang ditanggung perusahaan akibat yang timbul dari biaya bahan bakar kendaraan dan biaya pengiriman kelokasi tujuan.

Menurut [3], aktivitas produksi air mineral perlu dilakukan pengendalian produksi demi menjaga aktivitas perencanaan agar sesuai dengan perkiraan pada perhitungan teorema yang digunakan. Dalam hal ini, perlu didukung dengan cara yang optimal dalam merencanakan sistem persediaan air mineral untuk menjaga stok-stok yang sudah ditarget agar cepat sampai ketangan konsumen, untuk mencegah berhentinya penjualan [2]. Kegiatan produksi memerlukan peramalan untuk penentuan jumlah permintaan barang yang diproduksi [4], [5]. Selain itu digunakan sebagai langkah pertama dalam lingkup perencanaan dan pengendalian produksi barang [6]. Dengan adanya peramalan jumlah permintaan, memiliki tujuan untuk mengurangi timbulnya ketidakpastian agar mampu diperoleh suatu perkiraan pada kondisi lapangan [7], [8]. Oleh karena itu, kegiatan peramalan yang akurat dapat digunakan sebagai acuan yang dibutuhkan dalam pembuatan perencanaan dengan contoh yaitu: jika dalam peramalan permintaan meunjukkan jumlah permintaan yang naik dari data-data sebelumnya, maka perusahaan dapat mempersiapakn kebutuhan-kebutuhan apa saja yang diperlukan [9], [10]. Hal tersebut sebagai langkah antisipasi agar konsumen yang melakukan pembelian pada produk barang tersebut tidak kecewa, selain itu perusahaan tidak akan kehilangan pangsa pasar. Sebaliknya, jika dalam peramalan, proyeksi permintaan mengalami penurunan, perusahaan perlu mempersiapkan strategi-strategi agar penurunan permintaan barang dapat diminimalisir [11]. Strategi dibutuhkan agar mampu mempertahankan permintaan barang yang 
dibutuhkan, jika perusahaan tidak melakukan strategi yang baik, perusahaan akan kehilangan konsumen karena permintaan yang diharapkan tidak mampu mencapai kebutuhan konsumen.

Aktivitas perencanaan produksi membutuhkan konsep yang mampu memberikan gambaran tentang kebutuhan yang akan dicapai oleh perusahaan dalam rencana pengendalian produksi. Pengendalian produksi selain digunakan untuk mengendalikan produksi agar tidak melebihi unit yang diproduksi, juga sebagai langkah alternatif untuk meciptakan perencanaan unit produksi agar tidak terlalu lama menimbun digudang. Perencanaan produksi yang dilakukan perusahaan yaitu melakukan perhitungan peramalan diperlukan metode untuk melakukan perhitungan secara matematis. Metode yang digunakan secara matematis bersifat kuantitatif. Salah satu metode secara kuantitatif adalah Single Exponential Smoothing (SES) [12], dimana metode ini melakukan perhitungan peramalan pada data yang sudah diperoleh pada periode $(t+1)$ secara aktual pada periode $(t)$ kemudian ditambah dengan nilai penyesuaian besar kesalahan pada periode $(t)$ [5], [13], [14]. Menurut [5], metode Single Exponential Smoothing (SES) mampu digunakan untuk melakukan perhitungan perencanaan persediaan barang yang sedang diproduksi, dengan hal ini metode tersebut perlu dilakukan penerapan pada perhitungan persediaan air mineral sebagai langkah mengetahui jumlah yang perlu disediakan untuk konsumen. Sedangkan pada penilaian besar kecilnya kesalahan peramalan data permintaan peramalan menggunakan Mean Absolute Deviation (MAD) [15], [16]. Pada persediaan air mineral ketika dihitung dengan metode Single Exponential Smoothing (SES), perlu diberikan besar kecilnya kesalahan peramalan. Penentuan besar kecilnya peramalan digunakan agar dapat dicari nilai kesalahan peramalan paling kecil. Dari nilai kesalahan peramalan paling kecil, akan digunakan sebagai asumsi pada perencanaan perhitungan jumlah persediaan.

Perusahaan yang bernama PT. Akasha Wira International, Tbk adalah perusahaan yang bergerak dibidang produksi air minum dalam kemasan (AMDK) yang memiliki produk dengan tipe volume yang berbeda. Pada penelitian fokus perhitungan jumlah persediaan air mineral pada tipe volume $330 \mathrm{ml}$. Tujuan penelitian ini, yaitu untuk mengetahui peramalan jumlah permintaan pada produk air mineral $330 \mathrm{ml}$ shortneck dimasa mendatang menggunakan metode Single Exponential Smoothing (SES). Batasan masalah yaitu membahas jumlah permintaan dimasa mendatang semester I 2020, data yang digunakan diperoleh dari PT. Akasha Wira International pada Januari 2014 sampai dengan Desember 2019.

\section{Tinjauan Pustaka}

\subsection{Peramalan}

Peramalan (forecasting) adalah seni dan ilmu untuk memperkirakan kejadian di masa depan. Hal ini dapat dilakukan dengan melibatkan pengambilan data di masa lalu dan meenmpatkannya ke masa yang akan datang dengan suatuu bentuk model matematis. Bisa juga merupakan prediksi intuisi yang bersifat subjektif. Atau bisa juga dengan menggunakan kombinasi model matematis yang disesuaikan dengan pertimbangan yang baik dari seorang manajer [4].

\subsection{Tipe-Tipe Peramalan}

Tipe - Tipe Peramalan Organisasi pada umumnya menggunkan tiga tipe peramalan yang utama dalam pe rencanaan operasi di masa depan [4].

a. Peramalan Ekonomi 
Peramalan yang menjelaskan siklus bisnis dengan memprediksi tingkat inflasi, kesediaan uang, dana yang dibutuhkan untuk membangun perumahan, dan indikator perencannan lainnya.

b. Peramalan Teknologi

Peramalan yang memperhatikan tingkat kemajuan teknologi yang dapat meluncurkan produk baru yang menarik, membutuhkan pabrik dan peralatan baru. Peramalan ini biasanya memerlukan jangka waktu yang panjang dengan memperhatikan tingkat kemajuan teknologi.

c. Peramalan Permintaan

Proyeksi permintaan untuk produk atau layanan suatu perusahaan. Peramalan ini disebut juga peramalan penjualan, yang mengendalikan produksi, kapasitas, serta sistem penjadwalan dan menjadi input bagi perencanaan keuangan, pemasaran, dan sumber daya manusia.

\section{Metode Penelitian}

\subsection{Tempat dan Waktu Penelitian}

Penelitian dilakukan pada PT. Akasha Wira International pada bulan Januari 2020.

\subsection{Populasi dan Sampel}

Pada penelitian ini populasi yang digunakan yaitu Air mineral $330 \mathrm{ml}$ shortneck pada PT. Akasha Wira International, Tbk di Pasuruan, Jawa Timur. Sedangkan sampel pada penelitian yaitu data permintaan air mineral $330 \mathrm{ml}$ shortneck pada Januari 2014 sampai dengan Desember 2019 digunakan sebagai peramalan dimasa mendatang.

\subsection{Jenis dan Sumber Data}

Terkait dengan data yang digunakan sebagai berikut:

\section{a. Data kuantitatif}

Pada data kuantitatif adalah data yang diperoleh dari perusahaan terkait dengan data persediaan [17].

\section{b. Data Kualitatif}

Pada data kualitatif adalah data yang diperoleh dari perusahaan bersifat secara lisan maupun tulisan yang bukan bersifat angka, antara lain informasi tentang metode yang digunakan dalam penentuan persediaan [18].

\section{c. Data Primer}

Data primer yaitu data yang diperoleh langsung dari obyek penelitian dengan mengadakan pengamatan langsung atau wawancara [19].

\section{d. Data Sekunder}

Data sekunder yaitu data yang diperoleh secara tidak langsung melalui penelitian kepustakaan baik melalui dokumen-dokumen atau laporan tertulis serta informasi lainnya yang berhubungan dengan penelitian ini [19].

\subsection{Teknik Pengumpulan Data}

\section{a. Interview}

Merupakan suatu cara untuk mendapatkan data atau informasi dengan tanya jawab secara langsung pada orang yang mengetahui tentang obyek yang diteliti [20].

b. Dokumentasi 
Adalah bentuk penelitian yang dilakukan dengan mengumpulkan dokumen atau arsip-arsip perusahaan yang berhubungan dengan masalah persediaan dalam bentik file [20].

\subsection{Metode Analisis}

Metode analisis yaitu metode yang digunakan untuk membuat gambaran secara sistematis, faktual dan akurat mengenai suatu obyek yang akan diteliti yaitu:

a. $\quad$ Menghitung nilai kesalahan peramalan terhadap nilai $\alpha$ yang berbeda beda untuk menemukan satu nilai $\alpha$ yang menghasilkan kesalahan terkecil dengan metode perhitungan Mean Absolute Deviation (MAD). Metode untuk mengevaluasi metode peramalan menggunakan jumlah dari kesalahan kesalahan yang absolute. Mean Absolute deviation (MAD) mengukur ketepatan ramalan dengan merata-rata kesalahan dugaan (nilai absolut masingmasing kesalahan pada nilai Mean Absolute deviation (MAD) dapat dihitung dengan menggunakan rumus sebagai berikut [16]:

$$
M A D=\frac{\sum_{t=1}^{n}\left(T_{t}-Y^{\prime} t\right)}{n}
$$

Keterangan:

$\mathrm{T}_{\mathrm{t}} \quad=$ data permintaan pada periode

$\mathrm{Y}^{\mathrm{ee}}{ }_{\mathrm{t}} \quad=$ nilai ramalan pada periodet

$\mathrm{N} \quad=$ banyaknya periode

3.5.2. Single exponential smoothing (SES) dapat diartikan berdasarkan tahapan perhitungannya dimana nilai data ramalan pada periode $t+1$ merupakan nilai actual pada periode $t$ ditambah dengan penyesuaian yang berasal dari kesalahan nilai peramalan yang terjadi pada periode t. Pada metode ini dilakukan prediksi secara kuantitatif dengan pola data tidak stabil dan berdasarkan dere waktu dan metode ini digunakan untuk melakukan prediksi dengan cara melakukan rerata pada nilai masa lalu. Nilai peramalan dapat dicari dengan menggunakan rumus [8]:

Keterangan :

$$
F_{t+1}=a X_{t}+(1-a) F_{t}
$$

$\mathrm{X}_{\mathrm{t}} \quad=$ data permintaan pada periode $\mathrm{t}$

$\alpha \quad=$ kontanta pemulusan $(0<\alpha<1)$

$\mathrm{F}_{\mathrm{t}+1}=$ peramalan untuk periode $\mathrm{t}+1$

\section{Hasil dan Pembahasan}

Adapun hasil dari pelaksanaan penelitian terkait data permintaan semester 1 tahun 2014 sampai dengan semester 2 tahun 2019 sebagai berikut:

Tabel 1 Data Permintaan semester 1 tahun 2014 sampai semster 2 tahun 2019

\begin{tabular}{|c|c|}
\hline Tahun (Semester) & Permintaan (unit) \\
\hline 20141 & 158580 \\
\hline 20142 & 226539 \\
\hline 20151 & 207211 \\
\hline
\end{tabular}




\begin{tabular}{|c|c|}
\hline 20152 & 236229 \\
\hline 20161 & 227733 \\
\hline 20162 & 291392 \\
\hline 20171 & 173908 \\
\hline 20172 & 214089 \\
\hline 20181 & 193128 \\
\hline 20182 & 200199 \\
\hline 20191 & 172167 \\
\hline 20192 & 222380 \\
\hline Jumlah & 2523555 \\
\hline
\end{tabular}

(Sumber: olah data oleh penulis)

Pada data permintaan yang diperoleh dari PT. Akasha Wira International, Tbk mulai dari semester 1 tahun 2014 sampai dengan semester 2 tahun 2019. Data tersebut akan digunakan untuk meramalkan permintaan pada semester 1 tahun 2020.

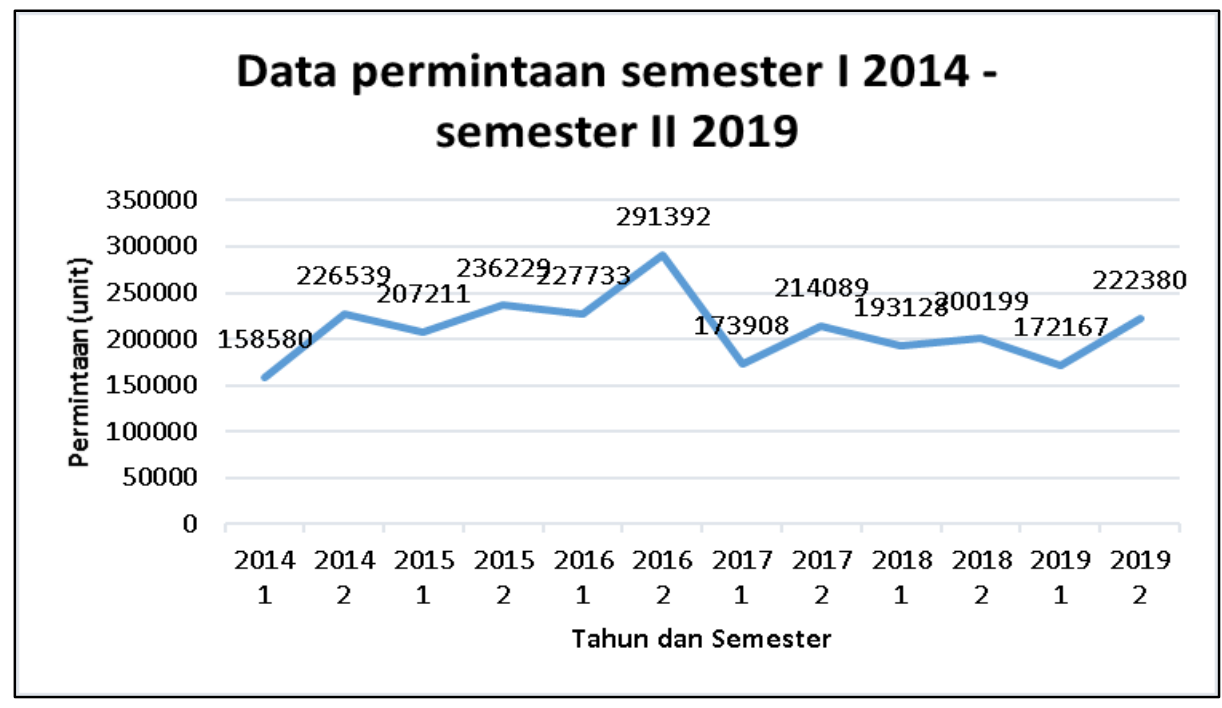

Gambar 1 Data permintaan semester I 2014 - semester II 2019

\subsection{Pengolahan Data}

\subsubsection{Perhitungan Single Exponential Smoothing (SES)}

Pada perhitungan dilakukan untuk mengetahui nilai kesalahan peramalan terhadap nilai $\alpha$. Nilai $\alpha$ yang digunakan adalah 0,$1 ; 0,2 ; 0,3 ; 0,4 ; 0,5 ; 0,6 ; 0,7 ; 0,8 ;$ dan 0,9 . Dengan perhitungan dicontohkan pada $\alpha=0,1$. Jumlah pada peramalan permintaan setiap semester dapat diperoleh menggunakan rumus (2) dengan $\alpha=0,1$, sebagai berikut :

a. Peramalan semester I tahun 2014

Pada tahap peramalan semester I 2014 ini, tidak ada data yang diketahui, oleh sebab itu hasil pada peramalan semester I tahun 2014 adalah 0.

b. Peramalan semester II tahun 2014

$$
\begin{aligned}
& F_{1+1}=a X_{1}+(1-a) F_{1} \\
& F_{2}=(0,1 \times 158580)+((1-0,1) \times 0)
\end{aligned}
$$




$$
\begin{aligned}
& F_{2}=15858+0 \\
& F_{2}=15858
\end{aligned}
$$

c. Peramalan semster I tahun 2015

$$
\begin{aligned}
& F_{2+1}=a X_{2}+(1-a) F_{2} \\
& F_{3}=(0,1 \times 226539)+((1-0,1) \times 15858) \\
& F_{3}=22653,9+14272,2 \\
& F_{3}=36926,1
\end{aligned}
$$

d. Peramalan semester II tahun 2015

$$
\begin{aligned}
& F_{3+1}=a X_{3}+(1-a) F_{3} \\
& F_{4}=(0,1 \times 207211)+((1-0,1) \times 36926,1) \\
& F_{4}=20721,1+33233,49 \\
& F_{4}=53954,59
\end{aligned}
$$

Pada perhitungan peramalan semester selanjutnya dengan penggunaan $\alpha=0,2$ sampai dengan 0,9 pada tabel sebagai berikut :

Tabel 2 Perhitungan Single Exponential Smoothing (SES) dengan Mean Absolute deviation (MAD)

\begin{tabular}{|c|c|c|c|c|c|c|c|c|c|}
\hline \multirow{2}{*}{\begin{tabular}{c} 
Semester $\begin{array}{c}\text { cen } \\
\text { dan } \\
\text { Tahun }\end{array}$ \\
\cline { 2 - 11 }
\end{tabular}} & 0.1 & 0.2 & 0.3 & 0.4 & 0.5 & 0.6 & 0.7 & 0.8 & 0.9 \\
\hline I 2014 & 0 & 0 & 0 & 0 & 0 & 0 & 0 & 0 & 0 \\
\hline II 2014 & 15858.0 & 31716.0 & 47574.0 & 63432.0 & 79290.0 & 95148.0 & 111006.0 & 126864.0 & 142722.0 \\
\hline I 2015 & 36926.1 & 70680.6 & 101263.5 & 128674.8 & 152914.5 & 173982.6 & 191879.1 & 206604.0 & 218157.3 \\
\hline II 2015 & 53954.6 & 97986.7 & 133047.8 & 160089.3 & 180062.8 & 193919.6 & 202611.4 & 207089.6 & 208305.6 \\
\hline I 2016 & 72182.0 & 125635.1 & 164002.1 & 190545.2 & 208145.9 & 219305.3 & 226143.7 & 230401.1 & 233436.7 \\
\hline II 2016 & 87737.1 & 146054.7 & 183121.4 & 205420.3 & 217939.4 & 224361.9 & 227256.2 & 228266.6 & 228303.4 \\
\hline I 2017 & 108102.6 & 175122.2 & 215602.6 & 239809.0 & 254665.7 & 264580.0 & 272151.3 & 278766.9 & 285083.1 \\
\hline II 2017 & 114683.2 & 174879.3 & 203094.2 & 213448.6 & 214286.9 & 210176.8 & 203381.0 & 194879.8 & 185025.5 \\
\hline I 2018 & 124623.7 & 182721.3 & 206392.6 & 213704.8 & 214187.9 & 212524.1 & 210876.6 & 210247.2 & 211182.7 \\
\hline II 2018 & 131474.2 & 184802.6 & 202413.2 & 205474.1 & 203658.0 & 200886.4 & 198452.6 & 196551.8 & 194933.5 \\
\hline I 2019 & 138346.6 & 187881.9 & 201749.0 & 203364.0 & 201928.5 & 200474.0 & 199675.1 & 199469.6 & 199672.4 \\
\hline II 2019 & 141728.7 & 184738.9 & 192874.4 & 190885.2 & 187047.7 & 183489.8 & 180419.4 & 177627.5 & 174917.5 \\
\hline I 2020 & $\mathbf{1 4 9 7 9 3 . 8}$ & $\mathbf{1 9 2 2 6 7 . 1}$ & $\mathbf{2 0 1 7 2 6 . 1}$ & $\mathbf{2 0 3 4 8 3 . 1}$ & $\mathbf{2 0 4 7 1 3 . 9}$ & $\mathbf{2 0 6 8 2 3 . 9}$ & $\mathbf{2 0 9 7 9 1 . 8}$ & $\mathbf{2 1 3 4 2 9 . 5}$ & $\mathbf{2 1 7 6 3 3 . 8}$ \\
\hline
\end{tabular}

(Sumber : Olah data oleh penulis

Dari perhitungan peramalan permintaan semester I tahun 2012 pada nilai $\alpha=0,1$ diperoleh sebesar 149793,8 unit. Pada nilai $\alpha=0,2$ diperoleh sebesar 192267,1 unit. Pada nilai $\alpha=0,3$ diperoleh sebesar 201726,1 unit. Pada nilai $\alpha=0,4$ diperoleh sebesar 203483,1 unit. Pada nilai $\alpha$ $=0,5$ diperoleh sebesar 204713,9 unit. Pada nilai $\alpha=0,6$ diperoleh sebesar 206823,9 unit. Pada nilai $\alpha=0,7$ diperoleh sebesar 209791,8 unit. Pada nilai $\alpha=0,8$ diperoleh sebesar 213429,5 unit dan nilai $\alpha=0,9$ diperoleh sebesar 217633,8 unit. Dari nilai $\alpha$, peramalan permintaan pada semester I tahun 2020 yang tertinggi yaitu sebesar 217633,8 unit. Untuk membuktikan $\alpha=0,9$ memiliki nilai tingkat kesalahan peramalan terkecil, diperlukan perhitungan perhitungan pada nilai Mean Absolute Deviation (MAD). 


\subsubsection{Perhitungan nilai Mean Absolute Deviation (MAD)}

Dalam perhitungan besarnya nilai kesalahan menggunakan metode Mean Absolute Deviation (MAD) dengan formula sebagai berikut :

a. Besar nilai kesalahan $\alpha=0,1$

$$
M A D=\frac{\sum_{t=1}^{n}\left(T_{t}-Y^{\prime}{ }_{t}\right)}{n}
$$

Pada perhitungan nilai kesalahan menggunakan $\alpha=0,1$, dengan asumsi sebaga berikut :

$n=$ banyaknya periode (didalam data yang diperoleh periode berjumlah 12 periode mulai dari semester I tahun 2014 sampai dengan semester II 2019. Periode tersebut perlu ditambah 1 periode karena 1 periode ini merupakan peramalan pada semester I tahun 2020). Oleh karena itu jumlah periode $n=13$.

$T_{t}=$ jumlah permintaan tiap semester yang diperoleh dari perusahaan yaitu ada 12 data permintaan. Perlu ditambah 1 data permintaan guna peramalan pada semester I tahun 2020 dengan nilai permintaan adalah 0 (nol).

$Y^{\prime}{ }_{t}=$ adalah proyeksi permintaan yang didapat pada perhitungan melalui metode Single Exponential Smoothing (SES) yang berjumlah 13 proyeksi permintaan dengan catatan pada nilai $n$ ke 1 diasumsikan 0 (nol) dalam penelitian ini, dikarenakan data permintaan sebelumnya tidak diperoleh.

Dilakukan perhitungan pada besar nilai kesalahan $\alpha=0,1$ sebagai berikut :

Tabel 3 Perhitungan besar nilai kesalahan $a=0,1$

\begin{tabular}{|c|c|c|c|}
\hline $\mathrm{n}$ & $\mathrm{Tt}$ & $Y^{\prime} t$ & Tt-Y't \\
\hline 1 & 158580 & 0 & 158580 \\
\hline 2 & 226539 & 15858 & 210681 \\
\hline 3 & 207211 & 36926.1 & 170285 \\
\hline 4 & 236229 & 53954.59 & 182274 \\
\hline 5 & 227733 & 72182.03 & 155551 \\
\hline 6 & 291392 & 87737.13 & 203655 \\
\hline 7 & 173908 & 108102.6 & 65805 \\
\hline 8 & 214089 & 114683.2 & 99406 \\
\hline 9 & 193128 & 124623.7 & 68504 \\
\hline 10 & 200199 & 131474.2 & 68725 \\
\hline 11 & 172167 & 138346.6 & 33820 \\
\hline 12 & 222380 & 141728.7 & 80651 \\
\hline 13 & 0 & 149793.8 & -149794 \\
\hline \multicolumn{3}{|c|}{ Jumlah } & 1348144 \\
\hline \multicolumn{3}{|c|}{ MAD } & 103703 \\
\hline
\end{tabular}

Untuk nilai kesalahan $\alpha=0,2$ sampai dengan $\alpha=0,9$ terjadi pada tabel sebagai berikut :

Tabel 4 Perhitungan besar nilai kesalahan a $=0,1$ sampai $a=0,9$

\begin{tabular}{|c|c|c|}
\hline No & $\begin{array}{c}\text { Kesalahan } \\
\text { Besar nilai }\end{array}$ & $\begin{array}{c}\text { permintaan } \\
\text { (unit) }\end{array}$ \\
\hline
\end{tabular}




\begin{tabular}{|l|l|l|}
\hline 1 & 0.1 & 103703 \\
\hline 2 & 0.2 & 59159 \\
\hline 3 & 0.3 & 36207 \\
\hline 4 & 0.4 & 23479 \\
\hline 5 & 0.5 & 15747 \\
\hline 6 & 0.6 & 10606 \\
\hline 7 & 0.7 & 6916 \\
\hline 8 & 0.8 & 4104 \\
\hline 9 & 0.9 & 1860 \\
\hline
\end{tabular}

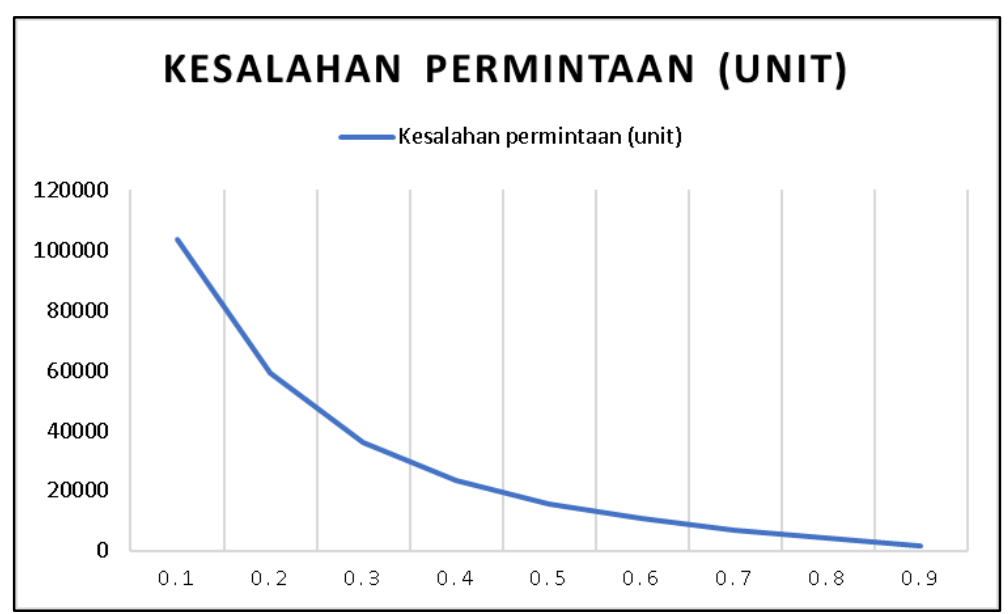

Gambar 2 Kesalahan permintaan

Dari perhitungan besar nilai kesalahan pada permintaan menggunakan metode Mean Absolute Deviation (MAD), didapatkan kesalahan peramalan permintaan terkecil didiperoleh pada $a=0,9$. Dalam hal ini, a= 0,9 digunakan sebagai acuan peramalan jumlah permintaan pada semester I tahun 2020.

\subsubsection{Peramalan Permintaan Semester 1 tahun 2020}

Setelah diketahui besar nilai kesalahan peramalan terkecil yaitu menggunakan $a=0,9$. Maka, dilakukan perhitungan sebagai berikut:

a. Peramalan semester I tahun 2014

Pada tahap peramalan semester I 2014 ini, tidak ada data yang diketahui, oleh sebab itu hasil pada peramalan semester I tahun 2014 adalah 0.

b. Peramalan semester II tahun 2014

$F_{1+1}=a X_{1}+(1-a) F_{1}$

$F_{2}=(0,9 \times 158580)+((1-0,9) \times 0)$

$F_{2}=142722+0$

$F_{2}=142722$

c. Peramalan semester I tahun 2015 


$$
\begin{aligned}
F_{2+1} & =a X_{2}+(1-a) F_{2} \\
F_{3} & =(0,9 \times 226539)+((1-0,9) \times 142722) \\
F_{3} & =203885,1+14272,2 \\
F_{3} & =218157,3
\end{aligned}
$$

d. Peramalan semester II tahun 2015

$$
\begin{aligned}
& F_{3+1}=a X_{3}+(1-a) F_{3} \\
& F_{4}=(0,9 \times 207211)+((1-0,9) \times 218157,3) \\
& F_{4}=186489,9+21815,73 \\
& F_{4}=208305,63
\end{aligned}
$$

e. Peramalan semester I tahun 2016

$$
\begin{aligned}
& F_{4+1}=a X_{4}+(1-a) F_{4} \\
& F_{4}=(0,9 \times 236229)+((1-0,9) \times 208305,63) \\
& F_{4}=212606,1+20830,56 \\
& F_{4}=233436,7 \\
& F_{5+1}=a X_{4}+(1-a) F_{5}
\end{aligned}
$$

f. Peramalan semester II tahun 2016

$$
\begin{array}{ll}
F_{4} & =(0,9 \times 227733)+((1-0,9) \times 233436,7) \\
F_{4} & =204959,7+23343,67 \\
F_{4} & =228303,4
\end{array}
$$

Pada perhitungan peramalan selanjutnya sampai diperoleh peramalan pada semester I tahun 2020 dengan nilai $a=0,9$ pada tabel sebagai berikut:

Tabel 5 Peramalan dengan a $=0,9$

\begin{tabular}{|c|c|}
\hline Semester dan Tahun & $a=0,9$ \\
\hline I 2014 & 0 \\
\hline II 2014 & 142722.0 \\
\hline I 2015 & 218157.3 \\
\hline II 2015 & 208305.6 \\
\hline I 2016 & 233436.7 \\
\hline II 2016 & 228303.4 \\
\hline I 2017 & 285083.1 \\
\hline II 2017 & 185025.5 \\
\hline I 2018 & 211182.7 \\
\hline II 2018 & 194933.5 \\
\hline I 2019 & 199672.4 \\
\hline II 2019 & 174917.5 \\
\hline I 2020 & $\mathbf{2 1 7 6 3 3 . 8}$ \\
\hline
\end{tabular}

(Sumber: Olah Data di PT Akasha Wira International, 2020)

Pada tabel peramalan dengan metode Mean Absolute Deviation (MAD), digunakan $a$ $=0,9$, dikarenakan memiliki kesalahan hitung dalam peramalan data permintaan terkecil dibanding pada nilai $a=0,1$ sampai dengan 0,8 . 


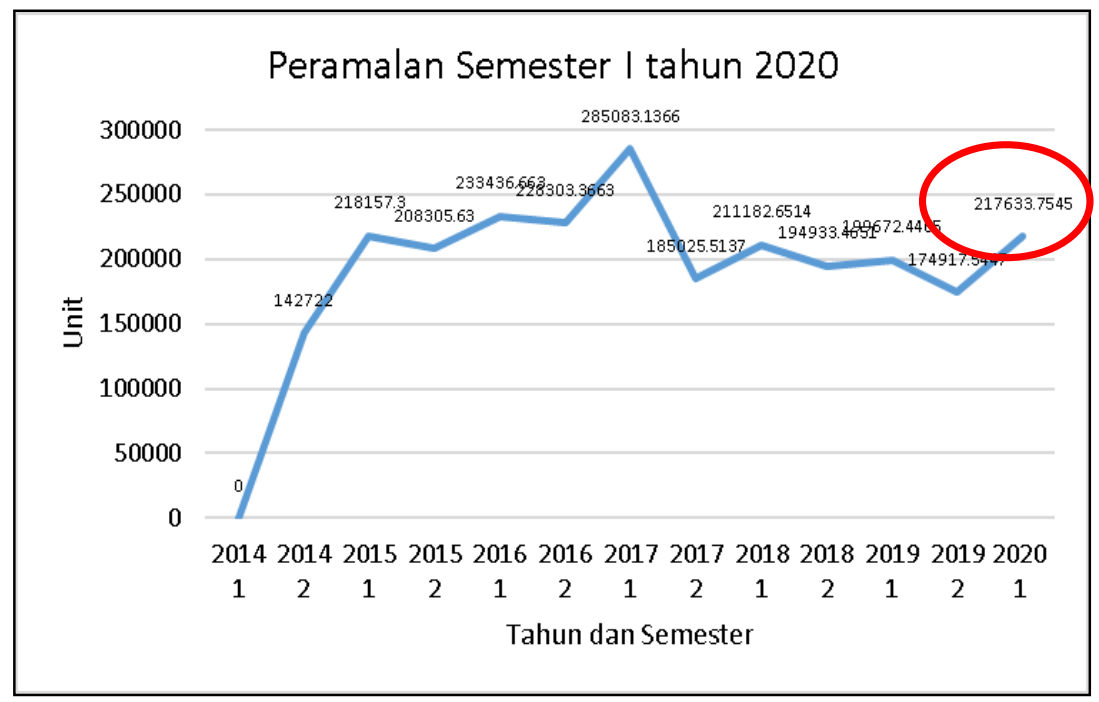

Gambar 3. Peramalan Semester 1 Tahun 2020

Pada peramalan menggunakan nilai Mean Absolute Deviation (MAD) $a=0,9$ diperoleh data permintaan pada semester I tahun 2020 sebesar 217633,8 unit dibulatkan menjadi 217634 unit. Dengan adanya peramalan jumlah permintaan tiap semesternya, perusahaan mampu memperkirakan biaya - biaya yang diperlukan untuk proses pengadaan bahan baku dan biaya - biaya operasional lainnya agar mampu dihemat untuk kepentingan selanjutnya. Dalam peramalan semester I tahun 2020, terjadi peningkatan proyeksi permintaannya, maka perusahaan diharapkan mampu memenuhi biaya - biaya yang diperlukan untuk mendukung proses produksi sebagai langkah agar tidak merugikan konsumen yang sudah menjadi prioritas dalam melakukan pembelian air mineral $330 \mathrm{ml}$ shortneck pada perusahaan PT. Akasha Wira International, Tbk.

\section{Kesimpulan dan Saran}

Berdasarkan penelitian yang sudah dilakukan pengolahan dan pembahasan, dapat disimpulkan pada peramalan semester I 2020 menggunakan metode Single Exponential Smoothing (SES) dengan besar nilai kesalahan yang digunakan $a=0,9$ adalah 217633,8 unit air mineral isi $330 \mathrm{ml}$ shortneck dibulatkan menjadi 2177634 unit. Sedangkan perhitungan Mean Absolute Deviation (MAD) $a=0,9$ bernilai 1860 unit kesalahan yang terjadi pada peramalan data permintaan di semester I tahun 2020. Saran bagi peneliti selanjutnya adalah dapat menerapkan berbagai metode untuk melakukan prediksi persediaan air minum dengan metode seperti time series, maupun software Minitab dan SPSS. Selain mempermudah juga dapat melakukan perhitungan secara cepat jika banyak data yang akan dilakukan perhitungan peramalan dengan pola penelitian seperti ini.

\section{Daftar Pustaka}

[1] Rayadi, "Persediaan Barang Dagang Pada Perusahaan Air Minum Mineral di Kota Pontianak,” Integr. Manuf. Syst., vol. 6, pp. 1-10, 2016.

[2] Fitriadi, “Optimasi Sistem Persediaan Produk Akhir Air Minum Dalam Kemasan (Amdk) Dengan Menggunakan Konsep Lean Manufacturing,” J. Optim., vol. 3, no. 4, pp. 39-47, 2018. 
[3] Amri, Trisna, and E. N. Harahap, "Perencanaan Pengendalian Produksi Air Minum Dalam Kemasan Menggunakan Metode Aggregate Planning," Malikussaleh Ind. Eng. J., vol. 1, no. 1, pp. 11-18, 2012.

[4] A. D. Rahajoe, "Forecasting feature selection based on single exponential smoothing using Wrapper method," Int. J. Adv. Comput. Sci. Appl., vol. 10, no. 6, pp. 139-145, 2019.

[5] S. D. Prestwich, S. A. Tarim, R. Rossi, and B. Hnich, "Forecasting intermittent demand by hyperbolic-exponential smoothing," Int. J. Forecast., vol. 30, no. 4, pp. 928-933, 2014.

[6] R. Y. Hayuningtyas, "Peramalan Persediaan Barang Menggunakan Metode Weighted Moving Average dan Metode Double Exponential Smoothing," None, vol. 13, no. 2, pp. 217-222, 2017.

[7] B. Putro, M. T. Furqon, and S. H. Wijoyo, "Prediksi Jumlah Kebutuhan Pemakaian Air Menggunakan Metode Exponential Smoothing ( Studi Kasus : PDAM Kota Malang ),” J. Pengemb. Teknol. Inf. dan Ilmu Komput. Univ. Brawijaya, vol. 2, no. 11, pp. 4679-4686, 2018.

[8] F. Sidqi and I. D. Sumitra, "Forecasting Product Selling Using Single Exponential Smoothing and Double Exponential Smoothing Methods," IOP Conf. Ser. Mater. Sci. Eng., vol. 662, no. 3, 2019.

[9] O. Rimpi, "Peramalan Produksi Ikan Laut di Kabupaten Pesisir Selatan Menggunakan Metode Pemulusan Eksponensial Tripel Tipe Brown,”Student Math. Dep., pp. 59-63, 2014.

[10] V. Ryanka Sutrisno, “Analisis Forecasting untuk Data Penjualan Menggunakan Metode Simple Moving Average dan Single Exponential Smoothing: Studi Kasus PT Guna Kemas Indah," 2013.

[11] D. Diniaty and Agusrinal, "Perancangan Strategi Pemasaran pada Produk Anyaman Pandan ( Studi Kasus: Home Industry Saiyo Sakato Di Kenagarian Padang Laweh Kecamatan Koto Vii Kabupaten Sawahlunto Sijunjung ),” J. Sains, Teknol. dan Ind., vol. 11, no. 2, pp. 175-184, 2014.

[12] D. M. Khairina, A. Muaddam, S. Maharani, and H. Rahmania, "Forecasting of Groundwater Tax Revenue Using Single Exponential Smoothing Method," E3S Web Conf., vol. 125, no. 201 9, pp. 1-5, 2019.

[13] C. L. Karmaker, "Determination of Optimum Smoothing Constant of Single Exponential Smoothing Model: A Case Study," Int. J. Res. Ind. Eng., vol. 6, no. 3, pp. 184-192, 2017.

[14] A. Hartono, "Perbandingan Metode single Exponential Smoothing Dan Metode Exponential Smoothing Adjusted For Trend (Holt's Method) Untuk Meramalkan 
Penjualan. Studi Kasus: Toko Onderdil Mobil 'Prodi, Purwodadi,'” J. EKSIS, vol. 5, no. 1, pp. 8-18, 2012.

[15] J. Segers, "On the asymptotic distribution of the mean absolute deviation about the mean," no. February, 2014.

[16] U. Khair, H. Fahmi, S. Al Hakim, and R. Rahim, "Forecasting Error Calculation with Mean Absolute Deviation and Mean Absolute Percentage Error," in Journal of Physics: Conference Series, 2017.

[17] M. P. Dr. Whidmurni, "Penelitian Kuantitatif," Pemaparan Metod. Kuantitatif, 2017.

[18] P. D. Sugiyono, metode penelitian kuantitatif, kualitatif,dan R\&D. 2016.

[19] Ali Maksum, “Data, Teknik Pengumpulan Data dan Instrumen Penelitian,” J. Cakrawala Kependidikan, no. agustus, p. 107, 2012.

[20] Sugiyono, “Teknik Pengumpulan Data," Metod. Penelit. Kuantitatif, Kualitatif dan R\&D, p. 137, 2014. 